\title{
Hydrogen peroxide controls Akt activity via ubiquitination/degradation pathways
}

\author{
SUN-YONG KIM ${ }^{1,2^{*}}$, SEUNGHEE BAE ${ }^{2 *}$, KEUN-HEE CHOI $^{3}$ and SUNGKWAN AN ${ }^{2,4}$ \\ ${ }^{1}$ Department of Molecular Cell Biology, Sungkyunkwan University School of Medicine, Samsung Biomedical \\ Research Institute, Suwon 440-746; ${ }^{2}$ Functional Genoproteome Research Centre, Konkuk University, \\ Seoul 143-701; ${ }^{3}$ Department of Beauty Art Design, Shinheung College, 117 Howon-dong, Uijeongbu-shi, \\ Gyeonggi-do 480-701; ${ }^{4}$ LIFEnGENE, Inc., Konkuk University, Seoul 143-701, Republic of Korea
}

Received May 14, 2011; Accepted June 17, 2011

DOI: 10.3892/or.2011.1439

\begin{abstract}
Akt is a well-established protein that regulates cell growth, survival and anti-apoptotic mechanisms. In this study, we demonstrated that hydrogen peroxide $\left(\mathrm{H}_{2} \mathrm{O}_{2}\right)$-induced oxidative stress regulates the activity of the anti-apoptotic protein Akt via the ubiquitin-proteasome degradation system. $\mathrm{H}_{2} \mathrm{O}_{2}$ induced cytotoxicity in $\mathrm{PC} 12$ cells and decreased the cellular protein and phosphorylation levels of Akt in a concentration- and exposure time-dependent manner. This downregulation was blocked by the proteasome inhibitor MG132 and the Akt-specific inhibitor LY294002. In addition, an in vivo ubiquitination assay revealed that the degradation of Akt was mediated by the ubiquitin-mediated proteasome pathway and further demonstrated that this ubiquitination was dependent on the phosphorylation status of Akt. Furthermore, the exogenously overexpressed active form of Akt, but not its inactive form, induced resistance to $\mathrm{H}_{2} \mathrm{O}_{2}$-mediated cell death. These results suggested that $\mathrm{H}_{2} \mathrm{O}_{2}$-induced cytotoxicity was mediated by active Akt degradation.
\end{abstract}

\section{Introduction}

Reactive oxygen species (ROS) is a broad term encompassing hydroxyl ('OH), alkoxy ( $\left.\mathrm{RO}^{*}\right)$, peroxyl ( $\left.\mathrm{ROO}\right)^{*}$ ), superoxide $\left(\mathrm{O}_{2}{ }^{*}\right)$, and nitroxyl ( $\mathrm{NO}^{*}$ ) radicals and nonradicals hydrogen peroxide $\left(\mathrm{H}_{2} \mathrm{O}_{2}\right)$ and organic hydroperoxide $(\mathrm{ROOH})(1)$. These ROS are byproducts of normal cellular metabolism that are generated by all aerobic organisms. ROS levels are strictly controlled by antioxidant enzymes and small antioxidant molecules

Correspondence to: Dr Sungkwan An, Functional Genoproteome Research Centre, Konkuk University, 1 Hwayang-dong, Gwangjin-gu, Seoul 143-701, Republic of Korea

E-mail: ansfgrc@konkuk.ac.kr

*Contributed equally

Key words: Akt, ubiquitination, oxidative stress, hydrogen peroxide, apoptosis such as glutathione. If this control is lost due to high levels of ROS generation or impairment of the antioxidant defense mechanism, ROS can lead to oxidative stress, resulting in high cellular toxicity (2). However, ROS have been demonstrated to function in inflammation, antimicrobial defense, and apoptosis (3-5). Furthermore, ROS function as second messengers involved in the responses of receptor tyrosine kinases to radiation or alkylating agents (6-8).

$\mathrm{H}_{2} \mathrm{O}_{2}$ is considered one of the most toxic ROS. Although $\mathrm{H}_{2} \mathrm{O}_{2}$ itself is not highly reactive, it can readily diffuse across cellular membranes, after which it is converted into highly reactive hydroxyl radicals through the Fenton reaction in the presence of metal ions (9). ROS-mediated cell death may have a contributory role in the development of the oxidative stress associated with many diseases such as Alzheimer's disease, Parkinson's disease, and lung airway diseases (10-12).

Akt is a serine/threonine kinase that functions in cell survival pathways to suppress apoptosis (13). After growth factor stimulation by factors such as insulin, epidermal growth factor, and insulin-like growth factor I, Akt is recruited to the plasma membrane and activated through PI3K/PDK1mediated phosphorylation at threonine 308 , followed by full activation via phosphorylation by TORC 2 at serine 473 $(14,15)$. Once Akt is activated, several antiapoptotic downstream targets including Bad, caspase-9, glycogen synthase kinase-3- $\beta$ (GSK-3 $\beta$ ), and forkhead transcription factors are phosphorylated and inactivated, thereby inhibiting cell death (16-19). Akt1 knockout mice are more susceptible to apoptosis induced by several genotoxic stresses, and the life span of $A k t 1^{-/-}$mice is shorter than that of wild-type mice (20).

$\mathrm{H}_{2} \mathrm{O}_{2}$ modulates the activity of cellular Akt. Several reports demonstrated that a basal level of ROS induces the phosphorylation of Akt, thereby protecting cells from oxidative stress-mediated damage (21-23). The phosphorylation/ activation of Akt precedes the inactivation of BAD, capase-9, forkhead transcription factors, and GSK-3 $\beta$ and the upregulation of nuclear factor- $\kappa B$ activity (16-19). In contrast, high levels of ROS induce the downregulation of the Akt signaling pathway, resulting in cell death. Excessive ROS levels induce the dephosphorylation/inactivation of Akt, resulting in Bax oligomerization, cytochrome $\mathrm{c}$ release from mitochondria, and the activation of caspase cascades. In addition to ROS-induced 
Akt dephosphorylation, two reports exist on ROS inhibited Akt activation through the degradation of cellular Akt $(24,25)$. Two different Akt degradation mechanisms have been reported. Mann et al (25) demonstrated that ROS generated by arsenic trioxide decreased Akt protein levels in a caspase-dependent manner; however, Martin et al (24) reported that capase-3 is dispensable for Akt degradation induced by ROS. However, their experiments were performed in different cell lines, namely NB4 cells and PC12 cells. This suggests that Akt degradation mechanisms are cell-type dependent and that the other known mechanisms can induce Akt degradation. Here, we found that the ubiquitin-proteasome system is a novel mechanism involved in Akt degradation during cell death induced by $\mathrm{H}_{2} \mathrm{O}_{2}$.

\section{Materials and methods}

Plasmids. The entire coding region of Akt was generated by PCR from cDNA synthesized from HeLa cells. Akt cDNA was cloned into the pcDNA3.1-Myc/His (Invitrogen, Carlsbad, CA) vector. The dominant-negative Akt (DN-Akt: T308A and S473A) was created using the QuickChange site-directed mutagenesis kit (Stratagene, Santa Clara, CA) according to the manufacturer's instructions. A HA-ubiquitin plasmid, pMT123, was kindly provided by Dr Dirk Bohmann (University of Rochester, Rochester, NY).

Cell culture and transfection. PC12 cells were grown in Dulbecco's modified Eagle's medium (Gibco ${ }^{\circledR}$, Invitrogen) containing $10 \%$ heat-inactivated horse serum (Gibco) and $5 \%$ fetal bovine serum (Gibco). Cells were transfected with the indicated plasmids using Hylimix (Dojindo, Kumamoto, Japan).

Antibodies and reagents. Primary antibodies against Akt, phospho-Akt (T473), and Myc tag were purchased from Cell Signaling Technology (Danvers, MA). HA tag antibody was obtained from Santa Cruz Biotechnology (Santa Cruz, CA), and GAPDH antibody was obtained from Abfrontier (Seoul, Korea). MG132 was purchased from Sigma-Aldrich (St. Louis, $\mathrm{MO}$ ), and $\mathrm{H}_{2} \mathrm{O}_{2}(30 \%)$ was purchased from Merck (Darmstadt, Germany). HRP-conjugated secondary antibodies were purchased from Cell Signaling Technology.

3-(4,5-dimethylthiazol-2-yl)-2,5-diphenyltetrazolium bromide (MTT) assay. PC12 cells were seeded onto 96-well plates $\left(100\right.$ cells $\left./ \mathrm{mm}^{2}\right)$ and starved with serum-free DMEM overnight. The next day, cells were treated with $\mathrm{H}_{2} \mathrm{O}_{2}$ at the indicated concentrations and times. Cell viability was measured by the MTT assay according to the manufacturer's instructions (Sigma-Aldrich).

Western blot analysis. Cells were lysed with lysis buffer (20 mM Tris-HCl, pH 7.5, 150 mM NaCl, 1 mM EDTA, 1 mM EGTA, 1\% Triton X-100, 0.1\% SDS, 1\% NP-40, 2.5 mM sodium pyrophosphate, $1 \mathrm{mM} \beta$-glycerophosphate, $1 \mathrm{mM} \mathrm{Na} \mathrm{VO}_{4}$, $2 \mathrm{mM}$ p-nitrophenyl phosphate, and a protease inhibitor cocktail) on ice for $30 \mathrm{~min}$. After centrifugation at $14,000 \mathrm{x} \mathrm{g}$ for $20 \mathrm{~min}$ at $4^{\circ} \mathrm{C}$, proteins in supernatants were separated on a 10 or $15 \%$ SDS-PAGE gel and transferred to a nitrocellulose membrane. Membranes were blocked with 5\% skim milk for
$1 \mathrm{~h}$ at room temperature and then incubated with primary antibodies (1:1000) overnight at $4^{\circ} \mathrm{C}$. After washing with $0.5 \%$ Tween-20 in Tris-buffered saline, membranes were incubated with HRP-conjugated secondary antibodies (1:5000). Proteins were visualized using ECL reagents (Amersham Biosciences, Piscataway, NJ) and detected with the LAS-3000 imager (Fuji, Tokyo, Japan).

In vivo ubiquitination assay. Akt-Myc/His plasmids together with HA-ubiquitin were cotransfected into PC12 cells as indicated in individual experiments. Twenty-four hours after transfection, cells were treated with $\mathrm{H}_{2} \mathrm{O}_{2}$ at the indicated concentrations and $10 \mu \mathrm{M}$ MG132 at various times. The cells were washed with PBS, lysed in $200 \mu \mathrm{l}$ of denaturing lysis buffer (50 mM Tris-Cl, pH 7.4; 0.5\% SDS, and $70 \mathrm{mM}$ $\beta$-mercaptoethanol) by vortexing, and then boiled for $15 \mathrm{~min}$ at $95^{\circ} \mathrm{C}$. The denatured lysates were diluted with $800 \mu \mathrm{l}$ of buffer A $\left(50 \mathrm{mM} \mathrm{NaH}_{2} \mathrm{PO}_{4}, 300 \mathrm{mM} \mathrm{NaCl}\right.$, and $10 \mathrm{mM}$ imidazole, $\mathrm{pH}$ 8.0) with protease inhibitor cocktail and MG132. The diluted lysates were incubated with Ni-NTA (Qiagen, Valencia, CA) beads overnight at $4^{\circ} \mathrm{C}$. The beads were washed with buffer $\mathrm{B}$ (50 $\mathrm{mM} \mathrm{NaH} \mathrm{PO}_{4}, 300 \mathrm{mM} \mathrm{NaCl}$, and $20 \mathrm{mM}$ imidazole, $\mathrm{pH}$ 8.0) five times. The proteins bound to the beads were eluted by boiling with SDS-PAGE sample buffer containing buffer $\mathrm{C}$ (50 $\mathrm{mM} \mathrm{NaH} \mathrm{PO}_{4}, 300 \mathrm{mM} \mathrm{NaCl}$, and $250 \mathrm{mM}$ imidazole, $\mathrm{pH}$ 8.0). The eluted proteins were immunoblotted with anti-HA antibody.

Statistical analysis. MTT assays were repeated six times. Data are expressed as mean \pm standard deviation (SD). Data were analyzed by analysis of variance (ANOVA) followed by the Tukey-Kramer method for multiple comparisons. $\mathrm{P}<0.05$ was considered statistically significant.

\section{Results}

$\mathrm{H}_{2} \mathrm{O}_{2}$ induces the apoptosis of PC12 cells and decreases the levels of Akt. We first examined the effect of $\mathrm{H}_{2} \mathrm{O}_{2}$ on cell viability. After seeding PC12 cells, the culture media was replaced with fresh serum free media, and cells were incubated overnight. Cells were then treated with $\mathrm{H}_{2} \mathrm{O}_{2}$ at the indicated concentrations for $24 \mathrm{~h}$, after which cell viability was analyzed using the MTT assay. As shown in Fig. $1 \mathrm{~A}, \mathrm{H}_{2} \mathrm{O}_{2}$ decreased the viability of $\mathrm{PC} 12$ cells in a concentration-dependent manner (Fig. 1A). In addition, $\mathrm{H}_{2} \mathrm{O}_{2}$ induced cytotoxicity in PC12 cells in a time-dependent manner (Fig. 1B). To investigate whether the decrease in cell viability was associated with regulation of Akt protein stability, we investigated the cellular levels of Akt and its phosphorylation status by using a biochemical immunoblotting assay with the indicated antibodies in $\mathrm{H}_{2} \mathrm{O}_{2}$ treated PC12 cells. $\mathrm{H}_{2} \mathrm{O}_{2}$ significantly decreased both the levels of total Akt and phospho-Akt (Fig. 1C, lanes 1 to 5). Next, to determine whether this downregulation was related to proteasomal degradation, cells were treated with a proteasome inhibitor, MG132, in the same manner as described for previous experiments. Of note, the decreases in Akt protein levels were fully restored by treatment with MG132 (Fig. 1C, lane 6 to 10). It has been reported that ROS generated by $\mathrm{H}_{2} \mathrm{O}_{2}$ induce Akt activation in the early response and subsequent Akt degradation in the later response (24). Thus, we sought to 
A

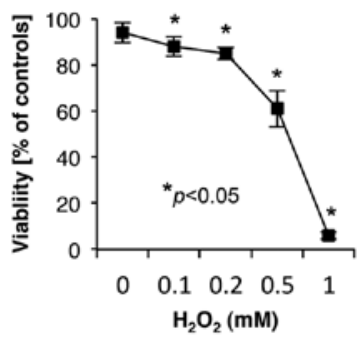

B

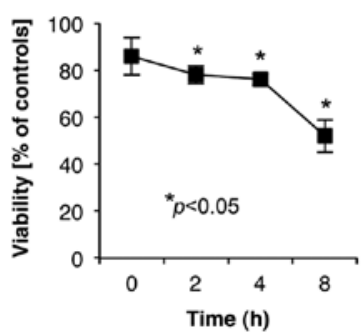

C

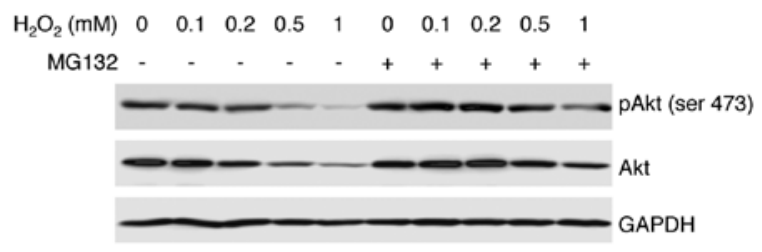

D

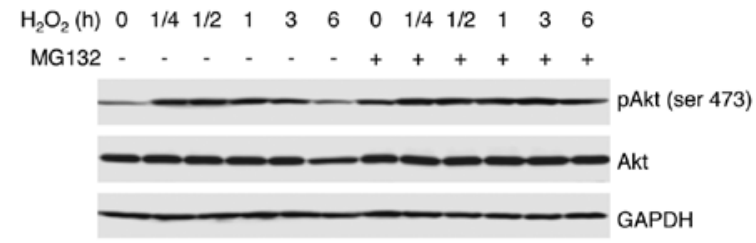

Figure 1. $\mathrm{H}_{2} \mathrm{O}_{2}$ induces apoptosis and decreases Akt protein levels. (A) $\mathrm{H}_{2} \mathrm{O}_{2}$ induced cytotoxicity in PC12 cells in a concentration-dependent manner. PC12 cells were cultured in the absence of serum overnight and treated with 100, 200, 500, and $1000 \mu \mathrm{M} \mathrm{H}_{2} \mathrm{O}_{2}$ for 24 h. (B) $\mathrm{H}_{2} \mathrm{O}_{2}$ induced cell death in an exposure time-dependent manner. PC12 cells were treated with $1 \mathrm{mM} \mathrm{H}_{2} \mathrm{O}_{2}$ for the indicated times. The number of live cells was estimated by the MTT assay. In (A) and (B), data are expressed as mean $\pm \mathrm{SD}$, and * indicates statistical significance compared with findings in control cells at each concentration and exposure time $(\mathrm{P}<0.05)$. (C) and (D) $\mathrm{H}_{2} \mathrm{O}_{2}$ induced Akt degradation via a proteasomal pathway. $\mathrm{PC} 12$ cells were treated with $\mathrm{H}_{2} \mathrm{O}_{2}$ at various concentrations $(\mathrm{C})$ and for various lengths of time (D) and then additionally treated with $10 \mu \mathrm{M}$ MG132 for $6 \mathrm{~h}$. Protein levels of phospho-Akt, Akt, and GAPDH (as a loading control) were measured via immunoblotting with antibodies as indicated.

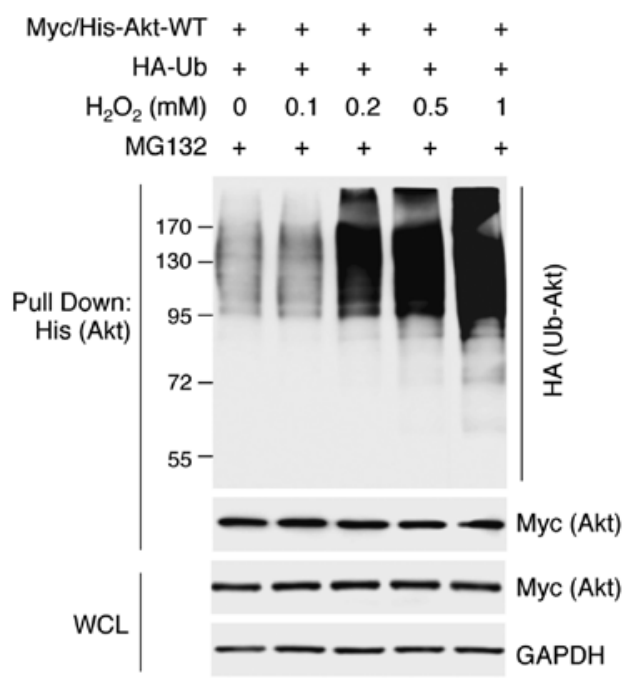

Figure 2. $\mathrm{H}_{2} \mathrm{O}_{2}$ induces Akt polyubiquitination. PC12 cells were cotransfected with plasmid for wild-type Akt (Myc/His-Akt-WT) together with the HA-ubiquitin plasmid as indicated. Twenty-four hours after transfection, cells were incubated in serum-free media and then treated with differen concentrations of $\mathrm{H}_{2} \mathrm{O}_{2}$ and $10 \mu \mathrm{M}$ MG132 for $6 \mathrm{~h}$. Cell lysates were subjected to in vivo ubiquitination analysis with $\mathrm{Ni}-\mathrm{NTA}$ beads. Ubiquitinated Akt was detected by immunoblotting with the anti-HA antibody.

determine the relationship between phosphorylation-mediated activation and proteasomal degradation of Akt in PC12 cells. Cells were stimulated with $1 \mathrm{mM} \mathrm{H}_{2} \mathrm{O}_{2}$ for various lengths of time and then incubated with or without MG132, after which the levels of phosphorylation and degradation of Akt were monitored. As shown in Fig. 1D (lanes 1 to 5), $\mathrm{H}_{2} \mathrm{O}_{2}$ induced Akt phosphorylation within $15 \mathrm{~min}$; however, this phosphorylation was decreased after $3 \mathrm{~h}$. Moreover, the degradation of Akt was attenuated by MG132 treatment (Fig. 1D, lane 6 to 10). In particular, at the 6-h time point, phosphorylated and total Akt levels were dramatically decreased, and their degradation was correlated with the significantly decreased cell viability at the same time point in Fig. $1 \mathrm{~A}$ and $\mathrm{B}$, suggesting that $\mathrm{H}_{2} \mathrm{O}_{2}$-induced cytotoxicity was related with the proteasomal degradation of Akt.

$\mathrm{H}_{2} \mathrm{O}_{2}$ induces Akt polyubiquitination. Proteasomal degradation is mediated through both ubiquitin-dependent and ubiquitin-independent mechanisms (26). To examine whether the ubiquitin-mediated process is involved in the proteasomal degradation of $\mathrm{Akt}, \mathrm{H}_{2} \mathrm{O}_{2}$-treated $\mathrm{PC} 12$ cell lysates were subjected to immunoprecipitation against $\mathrm{Akt}$, followed by immunoblotting with ubiquitin antibody. As shown in Fig. 2, high-molecular-weight smear bands representing polyubiquitination were detected for immunoprecipitated $\mathrm{Akt}$, and the levels of polyubiquitination were increased in an $\mathrm{H}_{2} \mathrm{O}_{2}$ concentration-dependent manner. In particular, the level of Akt ubiquitination was substantial after treatment with $1 \mathrm{mM} \mathrm{H}_{2} \mathrm{O}_{2}$, which was correlated with the degradation level in Fig. 1C. These results indicated that $\mathrm{H}_{2} \mathrm{O}_{2}$ induced the polyubiquitin-mediated proteasomal degradation of Akt in PC12 cells.

Activated Akt is a major target of $\mathrm{H}_{2} \mathrm{O}_{2}$-induced Akt ubiquitination. We further clarified the molecular details of $\mathrm{H}_{2} \mathrm{O}_{2}$-induced Akt ubiquitination in PC12 cells. According to previous data, a long exposure of cells to $\mathrm{H}_{2} \mathrm{O}_{2}$ induced ubiquitin-dependent degradation of phosphorylated and total Akt (24). These results suggested a relationship between phosphorylation and ubiquitination regarding $\mathrm{H}_{2} \mathrm{O}_{2}$-induced Akt degradation. We first examined the effect of LY294002, a 
A

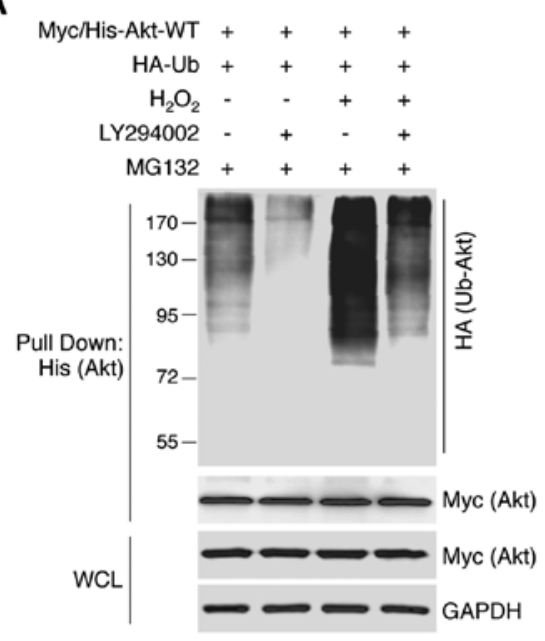

B

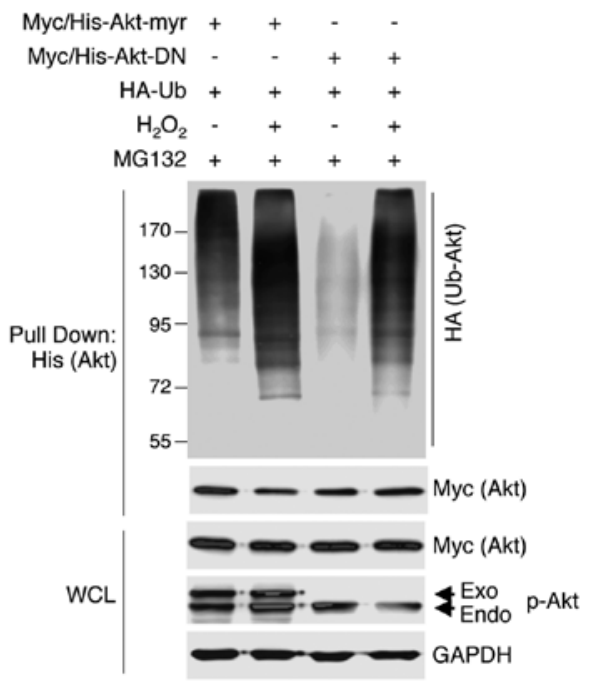

Figure 3. $\mathrm{H}_{2} \mathrm{O}_{2}$ induces ubiquitination of activated Akt. (A) $\mathrm{H}_{2} \mathrm{O}_{2}$-induced Akt ubiquitination was blocked by LY294002 treatment. PC12 cells were cotransfected with plasmids for wild-type Akt (Myc/His-Akt-WT) and the HA-ubiquitin plasmid as indicated. After $24 \mathrm{~h}$ of incubation, cells were starved overnight and pretreated with $10 \mu \mathrm{M} \mathrm{LY} 294002$, followed by stimulation with $1 \mathrm{mM} \mathrm{H}_{2} \mathrm{O}_{2}$ and $10 \mu \mathrm{M}$ MG132 for $6 \mathrm{~h}$. Equal amounts of lysate from the cells were subjected to an in vivo ubiquitination assay. Akt ubiquitination was examined by immunoblotting with anti-HA antibody. (B) Activated Akt, but not inactivated Akt, was efficiently ubiquitinated in response to $\mathrm{H}_{2} \mathrm{O}_{2}$ exposure. PC12 cells were cotransfected with Myc/His-Akt-Myr, Myc/His-Akt-DN, and HA-ubiquitin plasmids as indicated. After $24 \mathrm{~h}$ of incubation, the cells were treated $\mathrm{LY} 294002, \mathrm{H}_{2} \mathrm{O}_{2}$, and MG132 as indicated. Equal amounts of lysate from the cells were subjected to an in vivo ubiquitination assay. Akt ubiquitination was examined by immunoblotting with anti-HA antibody.

A

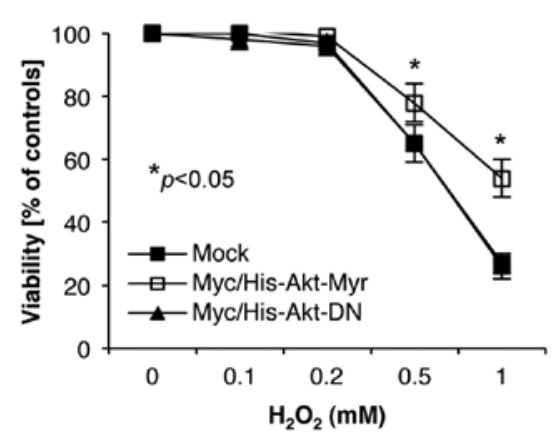

B

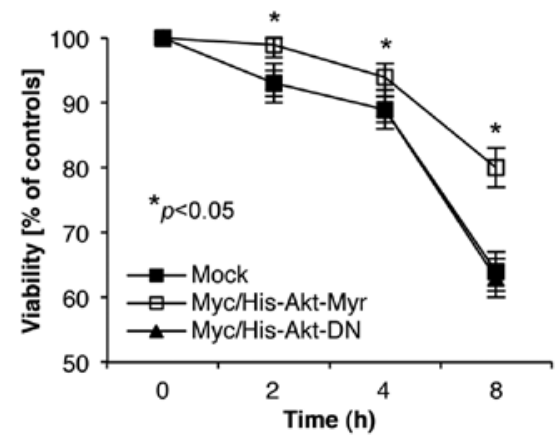

Figure 4. Akt activation prevents $\mathrm{H}_{2} \mathrm{O}_{2}$-induced cell death. Myc/His-Akt-Myr, Myc/His-Akt-DN, and control plasmids (Mock) were transfected into PC12 cells. After $24 \mathrm{~h}$ of incubation, $\mathrm{PC} 12$ cells were treated with $\mathrm{H}_{2} \mathrm{O}_{2}$ at the indicated concentrations (A) or with $1 \mathrm{mM} \mathrm{H}_{2} \mathrm{O}_{2}$ for the indicated lengths of time (B). The number of live cells was estimated by the MTT assay. In (A) and (B), data are expressed as means $\pm \mathrm{SD}$, and * indicates statistical significance in comparison with findings in control cells at each concentration and treatment time $(\mathrm{P}<0.05)$.

PI3K inhibitor that blocks Akt activation, on Akt ubiquitination in $\mathrm{PC} 12$ cells. As shown in Fig. $3 \mathrm{~A}, \mathrm{H}_{2} \mathrm{O}_{2}$ dramatically induced Akt ubiquitination relative to the control level; however, this ubiquitination was significantly blocked by additional LY294002 treatment. In addition, constitutively active myristorylated Akt (Myc/His-Akt-Myr) was strongly ubiquitinated in response to $\mathrm{H}_{2} \mathrm{O}_{2}$ stimulation in $\mathrm{PC} 12$ cells relative to the ubiquitination of DN Akt (Myc/His-Akt-DN) (Fig. 3B). These data indicated that $\mathrm{H}_{2} \mathrm{O}_{2}$ preferably induced the ubiquitination of phosphorylated (activated) Akt in PC12 cells.

Akt activity prevents cell death due to $\mathrm{H}_{2} \mathrm{O}_{2}$ stimulation. We previously demonstrated that $\mathrm{H}_{2} \mathrm{O}_{2}$ stimulation induced cytotoxicity and the ubiquitination of phosphorylated Akt. To confirm the effect of Akt activation on cell viability under $\mathrm{H}_{2} \mathrm{O}_{2}$ stimulation, constitutively activated Akt and DN Akt were overexpressed in PC12 cells, and then the viability of these cells was investigated using the MTT assay. As shown in Fig. 4, Myr-Akt-expressing PC12 cells, but not DN-Aktexpressing cells, exhibited resistance to $\mathrm{H}_{2} \mathrm{O}_{2}$-mediated cytotoxicity in a concentration- and time-dependent manner. Overall, these results suggested that $\mathrm{H}_{2} \mathrm{O}_{2}$ stimulation induced the downregulation of Akt activity by ubiquitin-mediated proteasomal degradation and the loss of Akt activity decreased cell viability.

\section{Discussion}

The present study demonstrated that $\mathrm{H}_{2} \mathrm{O}_{2}$-induced Akt degradation occurs through the ubiquitin-proteasome pathway, and this ubiquitination depends on the phosphorylation status of Akt. In PC12 cells, $\mathrm{H}_{2} \mathrm{O}_{2}$ treatment induced cell death in a concentration- and exposure time-dependent manner. In our experimental condition, $\mathrm{H}_{2} \mathrm{O}_{2}$ induced total and phosphoAkt degradation, which was blocked by MG132 treatment. Furthermore, an in vivo ubiquitination assay revealed that $\mathrm{H}_{2} \mathrm{O}_{2}$ 
enhanced Akt ubiquitination, and the ubiquitination level was reduced by LY294002, a specific PI3K inhibitor that blocks Akt phosphorylation. Phosphorylation-dependent proteolytic degradation of Akt was also investigated using ectopic expression of Myc/His-Akt-Myr and Myc/His-Akt-DN. The in vivo ubiquitination assay using these constructs demonstrated that ubiquitination induced by $\mathrm{H}_{2} \mathrm{O}_{2}$ stimulation occurred more strongly on active Akt-Myr than on inactive Akt-DN in vivo. In addition, overexpression of active Akt-Myr, but not unphosphorylated inactive Akt-DN, induced resistance to $\mathrm{H}_{2} \mathrm{O}_{2}$-depedent cell death, which indicates that the ubiquitinmediated proteasomal degradation of active Akt increases the sensitivity of cells to $\mathrm{H}_{2} \mathrm{O}_{2}$. Overall, our data indicate that $\mathrm{H}_{2} \mathrm{O}_{2}$ preferentially ubiquitinates phosphorylated Akt and promotes its degradation to induce cell death.

ROS generated by $\mathrm{H}_{2} \mathrm{O}_{2}$ regulates Akt activation via dephosphorylation and caspase-dependent and caspase-independent degradation pathways $(24,25)$. Akt is phosphorylated and activated early during $\mathrm{H}_{2} \mathrm{O}_{2}$ stimulation, but it is dephosphorylated and inactivated via caspase-mediated cleavage and caspase-3-independent degradation during long-term exposure to $\mathrm{H}_{2} \mathrm{O}_{2}$ (24). This downregulation including dephosphorylation and cleavage of $\mathrm{Akt}$ is correlated with apoptosis. However, the mechanisms by which total Akt and phosphorylated Akt levels are decreased in response to $\mathrm{H}_{2} \mathrm{O}_{2}$ stimulation have not been fully demonstrated, as dephosphorylation only induced Akt inactivation but not its degradation, and in caspase-3-deficient MCF-7 cells, Akt is more susceptible to $\mathrm{H}_{2} \mathrm{O}_{2}$-induced degradation. Additionally, Akt mutants (D108A, D119A), which are not cleaved by caspase-3, are still degraded in $\mathrm{H}_{2} \mathrm{O}_{2}$-stimuated PC12 cells (24). While the precise mechanism remains unclear, we demonstrated that Akt degradation in $\mathrm{H}_{2} \mathrm{O}_{2}$-treated $\mathrm{PC} 12$ cells was mediated through the ubiquitin/ proteasome degradation pathway.

Ubiquitin-proteasome dependent degradation is an irreversible pathway of protein degradation and is important for the regulation of many cellular functions, including cell cycle progression and cell growth (27). Polyubiquitination involves three components that participate in a cascade of ubiquitin transfer reactions: the E1 ubiquitin-activating enzyme, E2 ubiquitin-conjugating enzyme, and $\mathrm{E} 3$ ubiquitin-target protein ligase (27). A previous study reported that $\mathrm{H}_{2} \mathrm{O}_{2}$ stimulates ubiquitin-conjugating activity and the expression of genes for specific E2 and E3 proteins in skeletal muscle myotubes (28). That study revealed that the $\mathrm{H}_{2} \mathrm{O}_{2}$-mediated ubiquitin conjugation response required at least $4 \mathrm{~h}$ after exposure to $\mathrm{H}_{2} \mathrm{O}_{2}$ and persisted for at least $24 \mathrm{~h}$. To confirm these findings, our study included exposure of cells to $\mathrm{H}_{2} \mathrm{O}_{2}$ for specific time points between 4 and $24 \mathrm{~h}$ (exposure times of 6 and $24 \mathrm{~h}$ ). At these times, $\mathrm{H}_{2} \mathrm{O}_{2}$ significantly induced total Akt and phosphoAkt degradation after $\mathrm{H}_{2} \mathrm{O}_{2}$ stimulation, and their degradation was stimulated by polyubiquitination. Although the specific E3 ligase responsible for Akt ubiquitination in this condition was not investigated, the expression of the unknown E3 ligase gene might be induced by $\mathrm{H}_{2} \mathrm{O}_{2}$ exposure.

As Akt is phosphorylated quickly after $\mathrm{H}_{2} \mathrm{O}_{2}$ exposure, it suggests that Akt activation is one of the defense mechanisms against ROS toxicity. However, activated Akt levels are decreased during long-term exposure to $\mathrm{H}_{2} \mathrm{O}_{2}$ through ubiquitin-mediated degradation. We could not exclude the possibilities that activated Akt is dephosphorylated through ROS-induced phosphatase or that its levels are decreased via caspase in our experimental conditions. Phospho-Akt and total Akt levels were not completely recovered by MG132 treatment, suggesting that Akt activity is regulated through diverse mechanisms under ROS-induced apoptotic conditions. However, dephosphorylation is not a major event in the downregulation of Akt activity. Immunoblot assays in the present study and other studies demonstrated that total Akt levels were decreased by $\mathrm{H}_{2} \mathrm{O}_{2}$ exposure $(24,25)$. In addition, we found that Akt degradation occurred in response to high levels of $\mathrm{H}_{2} \mathrm{O}_{2}$ and long-term exposure to $\mathrm{H}_{2} \mathrm{O}_{2}$. In particular, the decrease in Akt levels is due to ubiquitin-mediated degradation of active Akt. In correlation with the results, constitutive expression of activated Akt abrogated the effects of ROS-induced cell death (Fig. 4). This suggests that the Akt degradation represents an irreversible step towards cell death opposed to the dephosphorylation-Akt inactivation event.

In summary, we demonstrated that $\mathrm{H}_{2} \mathrm{O}_{2}$ induces the degradation of active Akt via a ubiquitination-dependent pathway and this degradation regulates cellular Akt function as a negative regulator of $\mathrm{H}_{2} \mathrm{O}_{2}$-mediated cell death. These results suggest that $\mathrm{H}_{2} \mathrm{O}_{2}$-induced Akt ubiquitin-dependent degradation might accelerate the oxidative stress inducing cell apoptosis. Moreover, these findings provide potential evidence that Akt activity is regulated by ubiquitination.

\section{Acknowledgements}

We would like to thank Dr Dirk Bohmann (University of Rochester, Rochester, NY, USA) for kindly providing HA-ubiquitin plasmid pMT123. We are grateful to all other members in our research group for their support and advice regarding this study. This study was supported by grants from the Ministry of Education, Science, and Technology (grants 2011-0018427 and 2011-0002841 to S.A.) and the Korea Foundation for Cancer Research (grant KFCR-2009-002 to S.B.) of the Republic of Korea.

\section{References}

1. Simon HU, Haj-Yehia A and Levi-Schaffer F: Role of reactive oxygen species (ROS) in apoptosis induction. Apoptosis 5: 415-418, 2000.

2. Halliwell B: Biochemical mechanisms accounting for the toxic action of oxygen on living organisms: the key role of superoxide dismutase. Cell Biol Int Rep 2: 113-128, 1978.

3. Smith JA: Neutrophils, host defense, and inflammation: a doubleedged sword. J Leukoc Biol 56: 672-686, 1994.

4. Chanock SJ, el Benna J, Smith RM and Babior BM: The respiratory burst oxidase. J Biol Chem 269: 24519-24522, 1994.

5. Pierce GB, Parchment RE and Lewellyn AL: Hydrogen peroxide as a mediator of programmed cell death in the blastocyst. Differentiation 46: 181-186, 1991.

6. Coffer PJ, Burgering BM, Peppelenbosch MP, Bos JL and Kruijer W: UV activation of receptor tyrosine kinase activity. Oncogene 11: 561-569, 1995.

7. Knebel A, Rahmsdorf HJ, Ullrich A and Herrlich P: Dephosphorylation of receptor tyrosine kinases as target of regulation by radiation, oxidants or alkylating agents. EMBO J 15: 5314-5325, 1996.

8. Huang RP, Wu JX, Fan Y and Adamson ED: UV activates growth factor receptors via reactive oxygen intermediates. J Cell Biol 133: 211-220, 1996.

9. Valko M, Morris H and Cronin MT: Metals, toxicity and oxidative stress. Curr Med Chem 12: 1161-1208, 2005. 
10. Jenner P: Oxidative stress in Parkinson's disease and other neurodegenerative disorders. Pathol Biol (Paris) 44: 57-64, 1996.

11. Butterfield DA: Amyloid beta-peptide [1-42]-associated free radical-induced oxidative stress and neurodegeneration in Alzheimer's disease brain: mechanisms and consequences. Curr Med Chem 10: 2651-2659, 2003.

12. Rahman I, Morrison D, Donaldson K and MacNee W: Systemic oxidative stress in asthma, COPD, and smokers. Am J Respir Crit Care Med 154: 1055-1060, 1996.

13. Franke TF: PI3K/Akt: getting it right matters. Oncogene 27: 6473-6488, 2008.

14. Vanhaesebroeck B and Alessi DR: The PI3K-PDK1 connection: more than just a road to PKB. Biochem J 346: 561-576, 2000.

15. Bhaskar PT and Hay N: The two TORCs and Akt. Dev Cell 12: 487-502, 2007.

16. Datta SR, Dudek H, Tao X, et al: Akt phosphorylation of BAD couples survival signals to the cell-intrinsic death machinery. Cell 91: 231-241, 1997.

17. Fujita E, Jinbo A, Matuzaki H, Konishi H, Kikkawa U and Momoi T: Akt phosphorylation site found in human caspase-9 is absent in mouse caspase-9. Biochem Biophys Res Commun 264: 550-555, 1999.

18. Cross DA, Alessi DR, Cohen P, Andjelkovich M and Hemmings BA: Inhibition of glycogen synthase kinase-3 by insulin mediated by protein kinase B. Nature 378: 785-789, 1995.

19. Brunet A, Bonni A, Zigmond MJ, et al: Akt promotes cell survival by phosphorylating and inhibiting a Forkhead transcription factor. Cell 96: 857-868, 1999.

20. Peng XD, Xu PZ, Chen ML, et al: Dwarfism, impaired skin development, skeletal muscle atrophy, delayed bone development, and impeded adipogenesis in mice lacking Akt1 and Akt2. Genes Dev 17: 1352-1365, 2003.
21. Konishi $\mathrm{H}$, Matsuzaki $\mathrm{H}$, Tanaka M, et al: Activation of protein kinase B (Akt/RAC-protein kinase) by cellular stress and its association with heat shock protein Hsp27. FEBS Lett 410: 493-498, 1997.

22. Shaw M, Cohen $P$ and Alessi DR: The activation of protein kinase $\mathrm{B}$ by $\mathrm{H}_{2} \mathrm{O}_{2}$ or heat shock is mediated by phosphoinositide 3-kinase and not by mitogen-activated protein kinase-activated protein kinase-2. Biochem J 336: 241-246, 1998.

23. Wang $X, M c C u l l o u g h ~ K D$, Franke TF and Holbrook NJ: Epidermal growth factor receptor-dependent Akt activation by oxidative stress enhances cell survival. J Biol Chem 275: 14624-14631, 2000.

24. Martin D, Salinas M, Fujita N, Tsuruo T and Cuadrado A: Ceramide and reactive oxygen species generated by $\mathrm{H}_{2} \mathrm{O}_{2}$ induce caspase-3-independent degradation of Akt/protein kinase B. J Biol Chem 277: 42943-42952, 2002.

25. Mann KK, Colombo M and Miller WH Jr: Arsenic trioxide decreases AKT protein in a caspase-dependent manner. Mol Cancer Ther 7: 1680-1687, 2008.

26. Orlowski $M$ and Wilk S: Ubiquitin-independent proteolytic functions of the proteasome. Arch Biochem Biophys 415: 1-5, 2003.

27. Mani A and Gelmann EP: The ubiquitin-proteasome pathway and its role in cancer. J Clin Oncol 23: 4776-4789, 2005.

28. Li YP, Chen Y, Li AS and Reid MB: Hydrogen peroxide stimulates ubiquitin-conjugating activity and expression of genes for specific E2 and E3 proteins in skeletal muscle myotubes. Am J Physiol Cell Physiol 285: C806-C812, 2003. 